\title{
Adequate symptom relief justifies hepatic resection for benign disease \author{
Rinkes*
} \\ Bram Fioole, Marike Kokke, Richard van Hillegersberg and Inne HM Borel
}

Address: Department of Surgery (G.04.228), University Medical Centre Utrecht, PO Box 85500, 3508 GA Utrecht, The Netherlands

Email: Bram Fioole - bfioole@planet.nl; Marike Kokke - marikekokke@hotmail.com; Richard van

Hillegersberg - r.vanhillegersberg@umcutrecht.nl; Inne HM Borel Rinkes* - i.h.m.borelrinkes@umcutrecht.nl

* Corresponding author

Published: 01 April 2005

BMC Surgery 2005, 5:7 doi:10.1186/|47|-2482-5-7

This article is available from: http://www.biomedcentral.com/I47I-2482/5/7

(c) 2005 Fioole et al; licensee BioMed Central Ltd.

This is an Open Access article distributed under the terms of the Creative Commons Attribution License (http://creativecommons.org/licenses/by/2.0), which permits unrestricted use, distribution, and reproduction in any medium, provided the original work is properly cited.
Received: II January 2005

Accepted: 0I April 2005

\begin{abstract}
Background: The purpose of this study was to evaluate the long-term results of partial liver resection for benign liver lesions.

Methods: All patients operated on for benign liver lesions from 1991 to 2002 were included. Information was retrieved from medical records, the hospital registration system and by a telephonic questionnaire.

Results: Twenty-eight patients with a median age of $4 \mathrm{I}$ years (I7-7I) were operated on (M/F ratio $5 / 23$ ). The diagnosis was haemangioma in 8 patients, $\mathrm{FNH}$ in $6, \mathrm{HCA}$ in 13 and angiomyolipoma in I. Eight patients were known to have relevant co-morbidity. Median operating time was 207 minutes (45-360). The morbidity rate was $25 \%$ and no postoperative mortality was observed. Twenty-two patients (79\%) had symptoms (mainly abdominal pain) prior to surgery. Twenty-five patients were reached for a questionnaire. The median follow up was 55 months (4-I50). In 89\% of patients preoperative symptoms had decreased or disappeared after surgery. Four patients developed late complications.
\end{abstract}

Conclusion: Long-term follow up after liver surgery for benign liver lesions shows considerable symptom relief and patient satisfaction. In addition to a correct indication these results justify major surgery with associated morbidity and mortality.

\section{Background}

Partial liver resection is an accepted treatment for primary and secondary malignancies of the liver. In experienced hands this operation is associated with mortality rates of less than $5 \%$ and morbidity of approximately $30 \%[1-4]$.

Unlike malignant liver tumours, the indication for resection of benign hepatic lesions, including haemangiomas, focal nodular hyperplasia (FNH) and hepatocellular ade- nomas (HCA) remains controversial [5-7]. Indications for resection of benign liver masses include: 1) severe or progressive symptoms, 2) uncertain diagnosis with a suspicion for malignancy, and 3) risk of haemorrhage or rupture. If possible, it is important to discern whether the presenting symptoms are due to the liver lesion detected, before proceeding with surgical intervention. Several studies have reported about the indication for surgery in various benign hepatic tumours. However, less is known 
Table I: Predominant presenting symptoms in 28 patients

\begin{tabular}{lccccc}
\hline Symptom & Haemangioma $(\mathrm{n}=8)$ & $\mathrm{FNH}(\mathrm{n}=6)$ & HCA $(\mathrm{n}=13)$ & Angiomyolipoma $(\mathrm{n}=\mathrm{I})$ & Total $(\mathrm{n}=28)$ \\
\hline Abdominal pain & 7 & 4 & 7 & 0 & 18 \\
Swelling & $\mathrm{I}$ & $\mathrm{I}$ & 0 & 1 & 3 \\
Nausea & 0 & 0 & 1 & 0 & 1 \\
No symptoms & 0 & $\mathrm{I}$ & 5 & 0 & 6 \\
\hline
\end{tabular}

about the long-term results of surgical treatment, particularly regarding symptom relief.

The present study was undertaken to evaluate the longterm results of partial liver resections for benign liver lesions, with emphasis on the course of symptomatology, long-term complication rate, and patient satisfaction.

\section{Methods}

All patients treated by partial liver resection for benign lesions in the University Medical Centre Utrecht between January 1991 and December 2002 were included. Information about these patients was retrieved from medical records and the hospital registration system.

Preoperative parameters consisted of age, sex, diagnosis, co-morbidity, presenting symptoms and indication for resection. In the preoperative work up we have routinely performed physical diagnostic investigation, ultrasound and computed tomography (CT) to exclude other pathology causing the symptoms. On indication additional gastroscopy or endoscopic retrograde cholangiopancreatography was performed. The indications for resection of a haemangioma were persisting symptoms and rapid growth. After exclusion of other pain aetiology a period of 3 months observation was allowed to asses the persistence of the symptoms. In case of FNH the indications for resection were persisting symptoms and to exclude malignancy. HCA's were resected if symptomatic or larger than $5 \mathrm{~cm}$.

Date of resection, extent of resection, number of perioperative blood transfusions and duration of resection were considered perioperative parameters. A major resection was defined as a resection of three segments or more. Perioperative blood transfusion was defined as at least one unit of packed cells infused within 24 hours after surgery.

Documented postoperative parameters consisted of clinically relevant complications, postoperative mortality, duration of admission and follow up. Postoperative mortality was defined as in-hospital mortality. Long-term follow up was obtained by a telephonic questionnaire. Information was collected about the presenting symp- toms, the relief of these symptoms after surgery and the impact on physical and social activities. The limitations on physical and social activities as a result of the presenting symptoms were divided in severe, moderate and none. Moderate limitations were defined as limitations for activities at least once a week, while severely limited patients experienced daily restrictions. Symptom relief was defined as a decrease or absence of the presenting symptoms after surgery.

\section{Results}

A total of 28 patients were operated on for benign liver lesions. The diagnosis was a haemangioma in 8 patients $(29 \%)$, FNH in $6(21 \%)$, HCA in $13(46 \%)$ and angiomyolipoma in $1(4 \%)$. The group consisted of 23 female and 5 male patients with a median age of 41 years (range 17 $71)$. Eight patients (29\%) were known to have relevant comorbidity, including severe cardiac or pulmonary diseases, diabetes mellitus, hepatitis, liver fibrosis, adipositas and multiple sclerosis.

Twenty-two patients were known to have symptoms prior to surgery $(79 \%)$. The most frequent presenting symptom was upper abdominal pain (64\%). Other presenting symptoms are shown in table 1 . The most important indications for resection were symptoms and excluding malignancy (table 2). The symptoms mentioned in this table consisted of abdominal pain in all patients. Three patients with HCA presented with haemorrhage as a result of spontaneous rupture. One patient was immediately operated on. The other 2 patients were stabilized and resection was performed after the haematoma was resolved.

All operations concerned partial liver resections, of which 11 resections were major (39\%) (Table 3 ). The median operating time was 207 minutes (range 45-360). Eighteen procedures necessitated perioperative blood transfusions (median 2, range 0-16).

One patient underwent extended left hemihepatectomy for an asymptomatic, but rapidly growing giant haemangioma $(25 \mathrm{~cm})$. This major resection was accompanied by massive intraoperative haemorrhage from direct venous hepatocaval branches $(7500 \mathrm{ml})$. After the resection the 
Table 2: Indication for resection in 28 patients

\begin{tabular}{|c|c|c|c|c|c|}
\hline Indication & Haemangioma $(n=8)$ & $\mathrm{FNH}(\mathrm{n}=6)$ & $\mathrm{HCA}(\mathrm{n}=13)$ & Angiomyolipoma $(n=I)$ & Total $(n=28)$ \\
\hline Symptoms & 7 & 1 & 3 & 0 & 11 \\
\hline Excluding malignancy & 0 & 5 & 5 & I & II \\
\hline Haemorrhage & 0 & 0 & 3 & 0 & 3 \\
\hline Risk of malignant degeneration & 0 & 0 & 2 & 0 & 2 \\
\hline Size $\quad 0$ & I & 0 & 0 & 0 & I \\
\hline
\end{tabular}

Table 3: 28 Partial liver resections

\begin{tabular}{lccccc}
\hline & Extent of resection & & \\
\hline Diagnosis & Patients & L Hemi & R Hemi & Ext R & Segm \\
\hline Haemangioma & 8 & 1 & 1 & 1 & 5 \\
FNH & 6 & 0 & 2 & 0 & 0 \\
HCA & 13 & 0 & 0 & 0 & 9 \\
Angiomyolipoma & 1 & 1 & 7 & 1 & 0 \\
All & 28 & 2 & & 18 \\
\hline
\end{tabular}

L Hemi = Left hemihepatectomy

R Hemi = Right hemihepatectomy

$\mathrm{R}$ Ext = Extended right hemihepatectomy

Segm = Segmentectomy

* One patient treated with a central resection segment 4,5 and 8

Table 4: Seven patients with 8 postoperative complications

\begin{tabular}{ll}
\hline Complication & Patients \\
\hline Wound infection & 2 \\
Urinary tract infection & 2 \\
Bile leakage & 1 \\
Severe ascites & $\mathrm{I}$ \\
Pneumonia & $\mathrm{I}$ \\
Deep venous thrombosis & $\mathrm{I}$ \\
\hline Total & 8 \\
\hline
\end{tabular}

transected surface kept oozing. Therefore haemostasis was obtained by packing with gauzes. About 36 hours later the gauzes were removed. Further postoperative recovery was uneventful. A second patient underwent reoperation for wound dehiscence. The median hospital stay was 9.5 days (range 5-39). Seven patients developed one or more postoperative complications resulting in a morbidity rate of $25 \%$ (table 4 ). No postoperative mortality was observed.

During follow up one patient died as a result of a cause other than liver surgery. Three months after a left hemihepatectomy for a large tumour which turned out to be a angiomyolipoma this patient died of cerebral stroke. Of the remaining 27 patients we were able to contact 25 for a questionnaire (figure 1). The median follow up of the interviewed patients was 55 months (range 4-150). Six of the 25 interviewed patients had no symptoms prior to surgery and underwent resection because of an uncertain diagnosis of an incidentally discovered liver lesion. Before surgery 7 patients were severely limited in their physical activities as a result of the liver lesion, 5 were moderately limited and 13 were not limited. Considering social activities 4 patients were severely limited prior to surgery, 4 were moderately limited and 17 were not limited. After surgery the symptoms had decreased or disappeared in 17 of the 19 interviewed patients with preoperative symptoms (89\%). In two patients the symptoms were unchanged. One patient underwent partial liver resection for an adenoma. After the resection the preoperative abdominal pain never decreased. In a second patient preoperative abdominal pain did not decrease after resection of a large haemangioma. In these two cases the preoperative symptoms were probably not related to the liver lesion. Four of the 25 interviewed patients had developed late complications as a result of the operation. These complications consisted of a hypertrophic scar ( $\mathrm{n}=$ $2)$ and incisional hernia $(n=2)$. Twenty-three of 25 


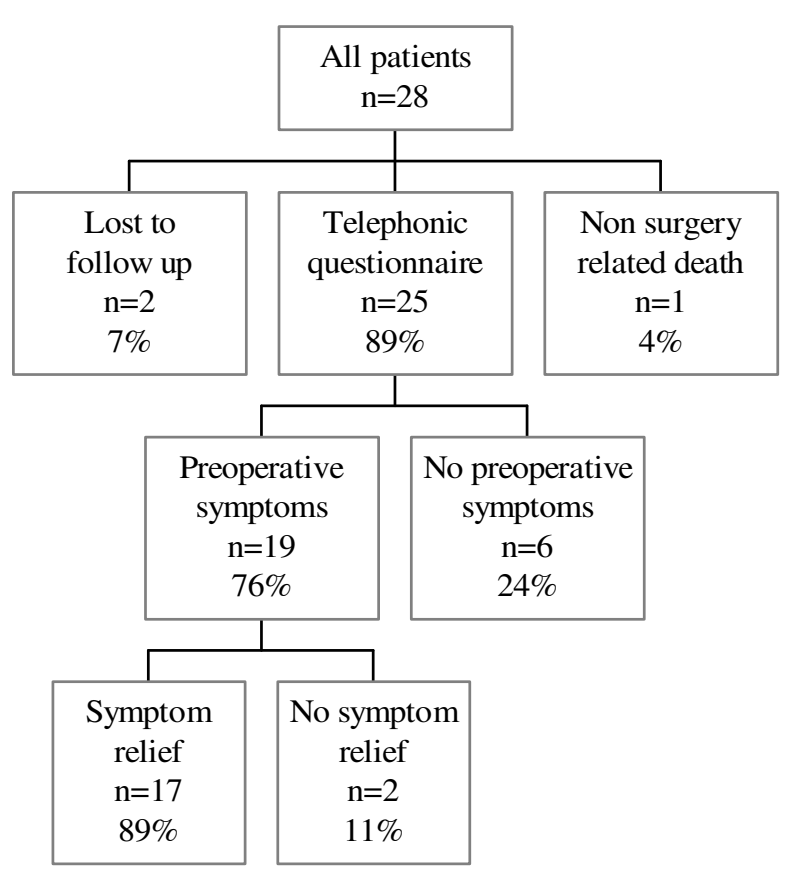

Figure I

Patients summary

interviewed patients were satisfied with the result of the resection $(92 \%)$.

\section{Discussion}

Symptom relief was observed in $89 \%$ of the patients (17/ 19), while in two patients the preoperative symptoms had not decreased. Only a few studies concerning long-term follow up of resections for benign liver tumours have been published. Terkivatan et al. described $80 \%$ symptom relief in surgically treated patients [5]. In this study surgery was only indicated in case of suspicion of malignancy, severe or increasing symptoms or a HCA larger than $5 \mathrm{~cm}$. They compared this group retrospectively with patients treated conservatively, of whom $34 \%$ presented with symptoms, e.g. non-specific complaints of fatigue and mild abdominal pain considered unrelated to the tumour. During long-term follow up $87 \%$ symptom relief was observed in the group who was treated conservatively. Charny et al. registered $93 \%$ symptom regression in patients who underwent partial liver resection for benign liver tumours and $86 \%$ symptom regression in patients who were observed for symptoms considered unrelated to the tumour or treated for unrelated conditions [8]. Therefore partial liver resection for a symptomatic liver lesion should only be performed when symptoms are most likely related to the lesion.

Because of the nature of benign liver tumours, clear indications are needed for partial liver resection, an operation associated with substantial postoperative morbidity and mortality. Indications for resection of a cavernous haemangioma of the liver are the development of complications, rapid growth, the presence of persisting symptoms or the need to establish a confident diagnosis. The potential for complications of a liver haemangioma (mainly rupture) is not an indication for resection of all liver haemangiomas. Spontaneous rupture of a haemangioma is infrequent and could be controlled with transcatheter hepatic artery embolization prior to resection [9]. As for rapid growth, we have operated on 1 patient with an asymptomatic, but rapidly growing haemangioma in our series. Little is known about the natural history of these large haemangiomas and resection can be very challenging, since they are at risk for massive intraoperative haemorrhage. In case of abdominal pain the main challenge is to determine whether these symptoms are due to the haemangioma or an associated condition [10-12]. Farges et al. described other pain aetiology in $54 \%$ of patients with symptomatic haemangiomas [7]. Gandolfi et al. observed only $7 \%$ symptomatic giant haemangiomas in their series [13]. Haemangiomas are not likely to cause diagnostic uncertainty. In our series we have not performed diagnostic resections for haemangiomas.

Unlike FNH, HCA is often symptomatic and is noted for its spontaneous rupture and malignant transformation. Looking at the potential complications, HCA's with a diameter of more than $5 \mathrm{~cm}$ should be resected, while for smaller HCA's and FNH observation is justifiable [6,1416]. Increasing size on radiographic imaging during observation is an indication for resection. FNH and HCA occur predominantly in females and are associated with long-term contraceptive steroid use [17]. This medication should be stopped, when FNH or a small HCA is not treated surgically. In case of FNH and HCA the most frequent indication for resection is the uncertain diagnosis of a hepatic mass with suspicion for malignancy. In addition to ultrasound, CT and MRI, positron emission tomography has proved to be a helpful modality distinguishing between benign and malignant liver lesions $[18,19]$. On the other hand, the use of needle biopsy should be reserved for atypical cases, since the limited material is rarely sufficient to exclude malignancy. In our series diagnostic uncertainty accounted for operation in 11 of 20 resected patients and was, together with symptoms, the main indication for resection. The final diagnosis after pathological examination of resected specimens was FNH in 5 patients, HCA in 5 and angiomyolipoma in 1. All 
HCA's were larger than $5 \mathrm{~cm}$, but no malignancies were observed.

\section{Conclusion}

We have shown in this consecutive series that partial liver resection for benign disease is a very effective procedure to relief invalidating abdominal symptoms. Benign liver lesions should only be resected when symptoms are most likely related to the lesion. In experienced centres the resection can be performed with acceptable morbidity and low mortality.

\section{Competing interests}

The author(s) declare that they have no competing interests.

\section{Authors' contributions}

BF designed the study, helped with the data acquisition and drafted the manuscript. MK carried out the data acquisition and participated in the study design. RH participated in the design of the study and in drafting and revising the manuscript. IBR conceived of the study and coordinated the draft and revision of the manuscript. All authors read and approved the final manuscript.

\section{References}

I. Jarnagin WR, Gonen M, Fong Y, DeMatteo RP, Ben-Porat L, Little S, Corvera C, Weber S, Blumgart LH: Improvement in perioperative outcome after hepatic resection: Analysis of 1,803 consecutive cases over the past decade. Ann Surg 2002, 236:397-407.

2. Belghiti J, Hiramatsu K, Benoist S, Massault PP, Sauvanet A, Farges O: Seven hundred forty-seven hepatectomies in the 1990s: an update to evaluate the actual risk of liver resection. J Am Coll Surg 2000, 191:38-46.

3. Scheele J, Altendorf A: Resection of colorectal liver metastases. Langenbeck's Arch Surg 1999, 384:3 I 3-327.

4. Fioole B, Liem MS, Hennipman A, Borel Rinkes IH: Partial liver resections: mortality, morbidity and risk factors for postoperative complications in 133 patients/137 operations; Utrecht University Medical Center 1991/2000. Ned Tijdschr Geneeskd 2002, 146:210-213.

5. Terkivatan T, de Wilt JH, de Man RA, van Rijn RR, Zondervan PE, Tilanus HW, IJzermans JN: Indications and long-term outcome of treatment of benign hepatic tumors. A critical appraisal. Arch Surg 200I, 136:1033-1038.

6. Nagorney DM: Benign hepatic tumors: Focal nodular hyperplasia and hepatocellular adenoma. World J Surg 1995, 19:13-18.

7. Farges $\mathrm{O}$, Daradkeh S, Bismuth $\mathrm{H}$ : Cavernous hemangiomas of the liver: Are there any indications for resection? World J Surg 1995, 19:19-24.

8. Charny CK, Jarnagin WR, Schwartz LH, Frommeyer HS, DeMatteo RP, Fong $\mathrm{Y}$, Blumgart LH: Management of 155 patients with benign liver tumors. Br J Surg 200I, 88:808-8I3.

9. Yamamoto T, Kawarada Y, Yano T, Noguchi T, Mizumoto R: Spontaneous rupture of hemangioma of the liver: treatment with transcatheter hepatic arterial embolization. Am J Gastroenterol 199I, 86: 1645.

10. Pietrabissa A, Giulianotti P, Campatelli A, Di Candio G, Farina F, Signori S, Mosca F: Management and follow-up of 78 giant hemangiomas of the liver. $\mathrm{Br}$ J Surg 1996, 83:915-918.

II. Brouwers MA, Peeters PM, De Jong KP, Haagsma EB, Klompmaker IJ, Bijleveld CM, Zwaveling JH, Slooff MJ: Surgical treatment of giant hemangioma of the liver. BrJ Surg 1997, 84:314-6.
12. Gedaly R, Pomposelli JJ, Pomfret EA, Lewis WD, Jenkins RL: Cavernous hemangioma of the liver. Anatomic resection vs enucleation. Arch Surg 1999, 134:407-4II.

13. Gandolfi L, Leo P, Solmi L, Vitelli E, Verros G, Colecchia A: Natural history of hepatic hemangiomas: clinical aand ultrasound study. Gut 1991, 32:677-680.

14. De Wilt JH, de Man RA, Lameris JS, Zondervan PE, Tilanus HW, IJzermans JN: Hepatocellular adenoma in 20 patients; recommendations for treatment. Ned Tijdschr Geneeskd 1998, I 42:2459-63.

15. Croes EA, van Gulik TM, Bosma A, de Wit LT, Gouma DJ: Treatment of 8 patients with an acute hemorrhage in a hepatocellular adenoma at the Academic Medical Center, Amsterdam. Ned Tijdschr Geneeskd 1998, 142:2463-2468.

16. De Wilt JH, de Man RA, Lameris JS, IJzermans JN: Focal nodular hyperplasia of the liver: assessment of diagnosis and treatment in 31 patients in 15 years. Ned Tijdschr Geneeskd 1996, 140:18-22.

17. Marks WH, Thompson N, Appleman H: Failure of hepatic adenomas (HCA) to regress after discontinuance of oral contraceptives. An association with focal nodular hyperplasia (FNH) and uterine leiomyoma. Ann Surg 1988, 208:190-5.

18. Delbeke D, Martin WH, Sandler MP, Chapman WC, Wright JK, Pinson CW: Evaluation of benign vs malignant hepatic lesions with positron emission tomography. Arch Surg 1998, 133:510-515.

19. Ho CL, Yu SC, Yeung DW: I I C-acetate PET imaging in hepatocellular carcinoma and other liver masses. J Nucl Med 2003, 44:213-22I.

\section{Pre-publication history}

The pre-publication history for this paper can be accessed here:

http://www.biomedcentral.com/1471-2482/5/7/prepub

Publish with Bio Med Central and every scientist can read your work free of charge

"BioMed Central will be the most significant development for disseminating the results of biomedical research in our lifetime. "

Sir Paul Nurse, Cancer Research UK

Your research papers will be:

- available free of charge to the entire biomedical community

- peer reviewed and published immediately upon acceptance

- cited in PubMed and archived on PubMed Central

- yours - you keep the copyright

Submit your manuscript here:

http://www.biomedcentral.com/info/publishing_adv.asp

BiolMedcentral 